\title{
Inhibitory effects of chemically modified heparin on the P-selectin-mediated adhesion of breast cancer cells in vitro
}

\author{
DONGHUI MI ${ }^{1,2^{*}}$, YANGUANG GAO ${ }^{3 *}$, SHENG ZHENG $^{1}$, XUEQING BA $^{1}$ and XIANLU ZENG ${ }^{1,2}$ \\ ${ }^{1}$ Institute of Genetics and Cytology, Northeast Normal University, Changchun, Jilin 130024; ${ }^{2}$ China-Japan Union \\ Hospital of Jilin University, Changchun, Jilin 130033; ${ }^{3}$ Department of Life Science and Engineering, \\ Harbin Institute of Technology, Harbin, Heilongjiang 150001, P.R. China
}

Received September 9, 2008; Accepted December 24, 2008

DOI: $10.3892 / \mathrm{mmr} 00000100$

\begin{abstract}
P-selectin plays a crucial role during hematogenous metastasis, and the blockade of P-selectin binding to its ligand can attenuate metastasis in various tumor models. Heparin or chemically modified heparins with decreased anticoagulant activities exhibit marked inhibitory effects on P-selectinmediated adhesion. Here, we prepared chemically modified heparins with reduced anticoagulant activities and investigated whether they effectively inhibited P-selectin binding to breast cancer cells under static and flow conditions. The results indicated that $\mathrm{P}$-selectin binding to ZR-75-30 cells was attenuated by chemically modified heparins in a sulfationdependent manner under static and flow conditions. Flow cytometric analysis with heparan sulfate-specific monoclonal antibody revealed that heparan sulfate-like proteoglycans on the tumor cell surface were not implicated in this process. Instead, other glycoproteins were found to serve as P-selectin ligands. These findings suggest that further detailed research involving chemically modified heparins with low or no anticoagulant activities is warranted, and that chemically modified heparins should be considered in the treatment of metastatic breast cancer disease, with P-selectin potentially being a good target.
\end{abstract}

\section{Introduction}

Selectins are adhesion molecules that normally recognize certain vascular mucin-type glycoproteins in mediating cellcell interaction among leukocytes, platelets and endothelial cells during inflammation, immune response and wound repair. However, accumulating evidence indicates that, in addition to

Correspondence to: Professor Xianlu Zeng, Institute of Genetics and Cytology, Northeast Normal University, Changchun, Jilin 130024, P.R. China

E-mail: zengx779@nenu.edu.cn

* Contributed equally

Key words: P-selectin, modified heparin, adhesion, breast cancer, heparan sulfate the above function, selectins facilitate metastasis by mediating the crucial interaction of cancer cells with platelets and endothelial cells (1). The formation of cancer cell-platelet complexes provides a shield that protects them from immune competent cells and favors cancer cell adhesion to the endothelium in a dynamic process (2). It is known that metastasis is a multistep cascade in which a variety of adhesion molecules, such as integrins, are involved. Whereas selectins primarily mediate the transient adhesive interactions of tethering and rolling, integrins and their ligands tend to mediate firm adhesion. More specifically, selectins are primarily responsible for the first step in cell adhesion, and their roles in the overall metastatic process are essential. Notable among these is P-selectin, a member of the selectin family that is expressed by activated platelets and endothelial cells. P-selectin plays a key role in mediating interaction between cancer cells, platelets and endothelial cells by interacting with its counterpart ligands. Accordingly, it was envisaged that the disruption of P-selectinligand interactions might be a good target for the blocking of metastasis $(3,4)$.

P-selectin has been shown to bind to several types of human cancer and human cancer-derived cell lines, including colon cancer, lung cancer, breast cancer, malignant melanoma, gastric cancer, tongue squamous cancer and neuroblastoma (5-8). P-selectin ligands have the potential to involve various types of compounds or molecules, including the Lewis tetrasaccharides, P-selectin glycoprotein ligand-1 (PSGL-1), heparan sulfate, chondroitin sulfate and sulfated moieties like glycolipid or sulfatides $(9,10)$. P-selectin antagonists have therefore been designed, including mAbs against $\mathrm{sLe}^{\mathrm{x}}, \mathrm{sLe}^{\mathrm{a}}$ and their mimetics, as well as recombinant PSGL-1 (11). Of the P-selectin antagonists, heparins and heparin-like molecules have shown promising results in various experiments in vitro and in vivo (12).

Heparin is a highly sulfated member of the glycosaminoglycan (GAG) family, and has been used as an anticoagulant since $1935(13,14)$. In addition to its antithrombotic activity, heparin exhibits a variety of biological activities, binding to a wide range of proteins and molecules via electrostatic interaction with polyanionic GAGs. Thus, many modified heparins that have reduced anticoagulant activities, but retain antimetastatic properties, have recently been developed to interrupt P-selectin-mediated adhesion $(11,15)$. To date, ample evidence indicates that certain chemically modified heparins 
with low or no anti-coagulant activities have the potential to inhibit metastasis but not primary tumor growth (16-18). Furthermore, Stevenson et al demonstrated that chemically modified non-anticoagulant heparins were more effective in reducing colon carcinoma metastasis than unfractionated heparin, indicating that chemically modified heparins are promising for therapeutic use (19).

Although it is well known that P-selectin can bind to breast cancer cells, it remains to be determined whether chemically modified heparins with decreased anticoagulant activities can effectively inhibit P-selectin binding, and whether they have a wide range of applications. In the present study, we employed human breast carcinoma cells to investigate the inhibitory effects of chemically modified heparins on P-selectin-mediated cell adhesion. The results indicated that P-selectin binding to ZR-75-30 cells was attenuated by chemically modified heparins in a sulfation-dependent manner. The data imply that P-selectin may be targeted for metastatic breast cancer treatment using chemically modified heparins with low or no anticoagulant activities.

\section{Materials and methods}

Heparin and chemically modified heparin. Porcine intestinal heparin ( $\mathrm{Mr}=18,000-20,000)$ was purchased from SigmaAldrich Inc. Periodate-oxidized, borohydride-reduced heparin (RO-heparin), carboxyl-reduced heparin (CR-heparin), 2-O, 3-O-desulfated heparin (2/3ODS-heparin) and N-desulfated, 2-O,3-O-desulfated heparin (N/2/3DS-heparin) were prepared and analyzed as previously described (15).

Proteins and antibodies. Recombinant human P-selectin IgG chimera protein $(\mathrm{P}-\mathrm{Fc}$ ) and a blocking $\mathrm{mAb}$ to P-selectin (9E1) were purchased from R\&D Systems Inc. A non-blocking mAb against P-selectin (AC1.2) was purchased from BD Pharmingen Inc. 10E4, a mAb against the native heparan sulfate chains of proteoglycans (murine $\operatorname{IgM}$ ), was generously provided by Dr Guido David. CSLEX-1, a mAb against $\mathrm{SLe}^{\mathrm{x}}$ (murine IgM), was a kind gift from Dr Olivier Spertini. The anti-PSGL-1 antibody KPL1 (murine $\mathrm{IgG}_{1}$, Santa Cruz Biotechnology Inc.), was commercially obtained. Mouse IgM isotype control and FITC-conjugated Ab against mouse IgM were purchased from Sigma-Aldrich Inc., and human IgG and mouse IgG isotype control FITC-labeled goat anti-human IgG and anti-mouse IgG were purchased from Jackson Immunoresearch Laboratories Inc.

Cell lines. The human breast carcinoma cell line ZR-75-30 and $\mathrm{CHO}$ cells were purchased from the Cell Bank of the Type Culture Collection of the Chinese Academy of Science (P.R. China) and grown in RPMI-1640 medium (Gibco) supplemented with $10 \%$ heat-inactivated fetal bovine serum (FBS), $100 \mathrm{U} / \mathrm{ml}$ penicillin and $0.1 \mathrm{mg} / \mathrm{ml}$ streptomycin (Life Technologies) at $37^{\circ} \mathrm{C}$ in a humidified incubator with a $5 \%$ $\mathrm{CO}_{2}$ atmosphere. Cells were passaged by mild trypsinization $(0.25 \%$ trypsin $)$ and harvested with 2 mM EDTA. To obtain $\mathrm{CHO}$ cells expressing human $\mathrm{P}$-selectin, the $\mathrm{CHO}$ cells were transiently transfected with human P-selectin cDNA by PolyFect Transfection Reagent (Qiagen) according to the manufacturer's instructions.
Flow cytometry. Cells were harvested and washed twice with PBS ( $1 \mathrm{mM} \mathrm{CaCl}_{2}, 1 \mathrm{mM} \mathrm{MgCl}$, 10 mM HEPES, pH 7.4), then counted and resuspended in culture medium at a final concentration of $5 \times 10^{6} \mathrm{cells} / \mathrm{ml}$. For P-selectin binding assay, approximately $5 \times 10^{5}$ cells were incubated in $100 \mu 1$ culture medium containing $0.3 \mu \mathrm{g}$ P-Fc or human $\mathrm{IgG}$ at room temperature (RT) for $30 \mathrm{~min}$, followed by FITC-labeled goat anti-human $\operatorname{IgG}(2 \mu \mathrm{g} / \mathrm{ml})$ for $30 \mathrm{~min}$. Subsequently, cells were washed twice, and 10,000 cells were collected for flow cytometric analylsis (FACScan, Beckman-Coulter, USA). For inhibition experiments, $\mathrm{P}-\mathrm{Fc}$ was pre-incubated with $1 \mu \mathrm{g}$ of $9 \mathrm{E} 1$ or $\mathrm{AC} 1.2$, or with various concentrations of modified heparins at RT for $30 \mathrm{~min}$. To detect the presence or absence of P-selectin ligands on the tumor cell surface, cells were stained with 1-2 $\mu \mathrm{g}$ of murine $\operatorname{IgM}$, murine $\operatorname{IgG}, 10 \mathrm{E} 4$, CSLEX-1 or KPL1, followed by FITC-conjugated Ab against murine $\operatorname{IgM}$ or $\operatorname{IgG}$, then analyzed by FACScan as described previously.

Inhibition of sulfate biosynthesis. Cells were washed with sulfate-free 1640 medium (Gibco) supplemented with 10\% FBS and $100 \mathrm{mM}$ sodium chlorate (Sigma), and cultured in the same medium for $2 \mathrm{~h}$. After being transferred to fresh 1640 medium, the cells were further cultured overnight. These treated cells were then harvested as described above for future use.

Enzyme treatment. Tumor cells ( $10^{7}$ cells $/ \mathrm{ml}$ in 1640 medium) were simultaneously treated with $5 \mathrm{U} / \mathrm{ml}$ heparinases I, II and III in the presence of a mixture of protease inhibitors $(10 \mathrm{mg} / \mathrm{ml}$ leupeptin, $20 \mathrm{mg} / \mathrm{ml}$ aprotinin and $10 \mathrm{mM}$ benzamidine) at $37^{\circ} \mathrm{C}$ for $1 \mathrm{~h}$ with end-to-end rotation. To remove terminal cell surface sialic acid residues, each aliquot $(50 \mu 1)$ of tumor cells ( $10^{7}$ cells $/ \mathrm{ml}$ in 1640 medium) was incubated with $0.1 \mathrm{U} / \mathrm{ml}$ neuraminidase at $37^{\circ} \mathrm{C}$ for $90 \mathrm{~min}$. To assess the contribution of glycoproteins, tumor cells were incubated with tissue culture grade trypsin at $20 \mu \mathrm{g} / \mathrm{ml}$ at $37^{\circ} \mathrm{C}$ for $90 \mathrm{~min}$ (20). After treatment with enzymes, the cells were washed twice with PBS/BCS ( $1 \mathrm{mM} \mathrm{CaCl}_{2}, 1 \mathrm{mM} \mathrm{MgCl}$ and $1 \%$ heat-inactivated FBS), resuspended in medium at a concentration of $5 \times 10^{6}$ cells/ $\mathrm{ml}$, and stained for detection by flow cytometry as previously described.

Laminar flow adhesion assay. The adhesion of tumor cells to transfected CHO cells or anchored-platelets expressing P-selectin under flow conditions $\left(0.3 \mathrm{dyn} / \mathrm{cm}^{2}\right)$ was measured by real-time video microscopy as described previously (21). The number of bound cells was quantified from videotape recordings of 10-20 fields of view obtained at the end of a 3 -min perfusion. For inhibition assays, $\mathrm{CHO}$ cell layers or activated platelet layers were pre-treated with mAb $(20 \mu \mathrm{g} / \mathrm{ml})$ or with various concentrations of modified heparins for $30 \mathrm{~min}$ at RT. The given data represent the average number of counted arrested cells in the fields of view. For certain experiments, the given values were corrected for the average number of arrested cells in the absence of mAbs, heparin, or modified heparins.

Statistical analysis. Data are expressed as the means \pm SE. Statistical analysis was performed using one-way ANOVA. $\mathrm{P}<0.01$ was considered to be statistically significant. 


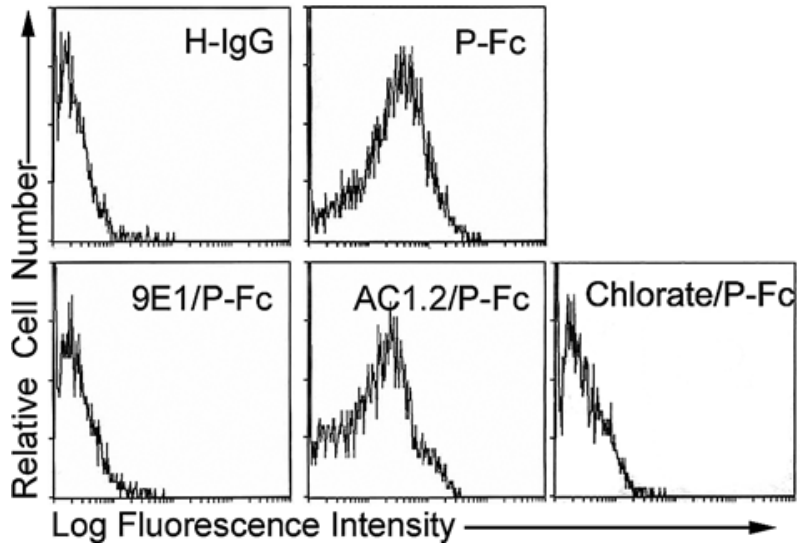

Figure 1. Interaction of P-selectin with ZR-75-30 cells. Interaction of P-selectin chimeras with $293 \mathrm{~T}$ cells was analyzed by flow cytometry in the presence of P-selectin blocking mAb (9E1) or non-blocking mAb (AC1.2). For sulfated inhibition of tumor cells, ZR-75-30 cells were pre-treated with sodium chlorate (Chlorate). An isotype-matched human IgG was used as a negative control $(1.5 \%)$. The results are representative of three independent experiments.

Table I. Sulfate content of modified heparins was determined by ion chromatography. Values are the means \pm SD of three separate experiments.

\begin{tabular}{ll}
\hline Modified heparins & Sulfate content (\%) \\
\hline Heparin & $27.9 \pm 0.03$ \\
RO-heparin & $27.1 \pm 0.02$ \\
CR-heparin & $25.2 \pm 0.01$ \\
2/3ODS-heparin & $19.3 \pm 0.04$ \\
N/2/3DS-heparin & $15.7 \pm 0.02$ \\
\hline
\end{tabular}

\section{Results}

Modified heparin inhibits the adhesion of breast carcinoma cells to P-selectin under static conditions. As documented previously, P-selectin binds to various types of tumor cells, including human breast carcinoma ZR-75-30 cells (22). In the present study, we first examined the interaction of ZR-75-30 cells with recombinant human P-selectin IgG chimera proteins (P-Fc) by flow cytometry. Compared to the human IgG control, P-Fc bound to ZR-75-30 cells (Fig. 1). The percentage of positive cells binding to P-selectin was $78.2 \%$. Pre-incubation of P-Fc with a blocking mAb (9E1), but not a non-blocking $\mathrm{mAb}$ (AC1.2), inhibited this binding, indicating the binding specificity of P-selectin to ZR-75-30 cells. As well, the treatment of tumor cells with sodium chlorate reduced P-selectin reactivity almost to the levels of the human $\mathrm{IgG}$ control (1.5\%). This indicates the requirement of sulfation in P-selectin binding.

We previously showed that heparin or chemically modified heparins inhibited P-selectin-mediated adhesion $(15,21)$. In this study, we prepared four chemically modified heparin deriva-tives with low anticoagulant activities (data not shown), including RO-heparin, CR-heparin, 2/3ODS-heparin and N/2/3DS-heparin, using various well-established methods. The sulfate content of each chemically modified heparin was

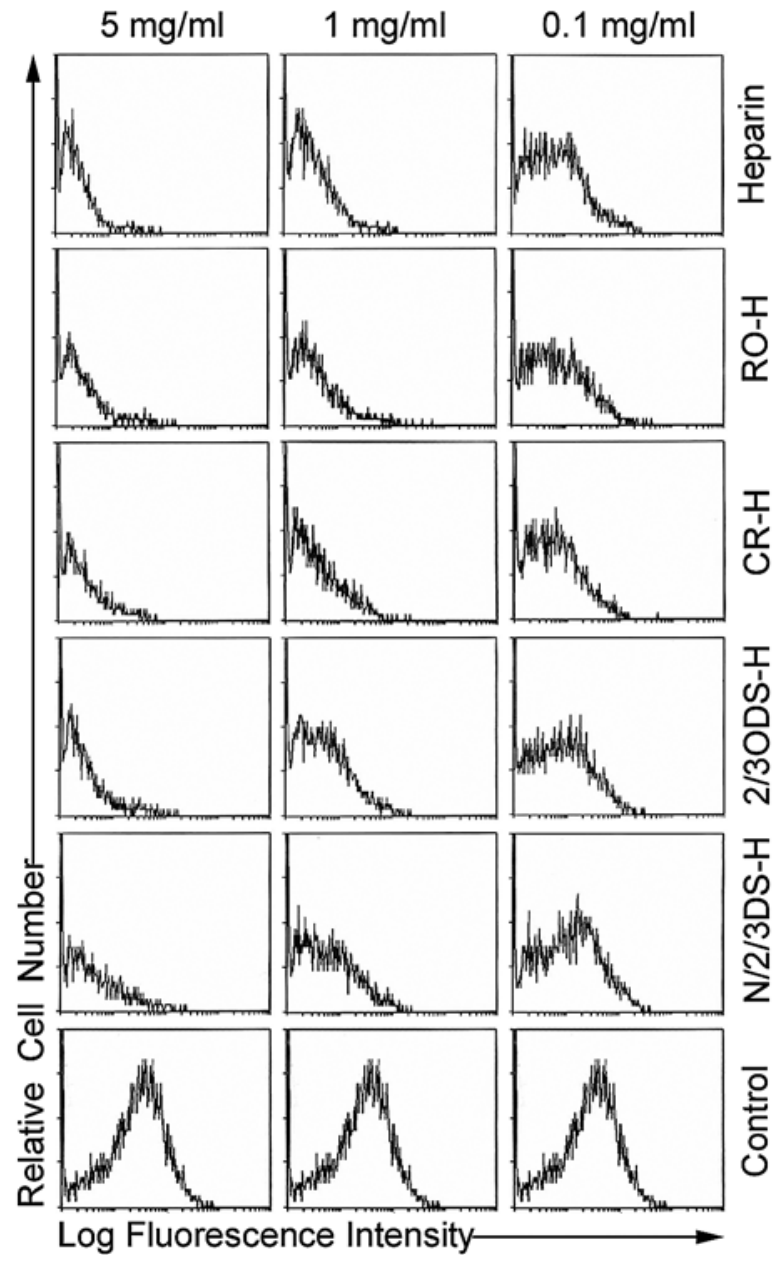

Figure 2. Effect of chemically modified heparins on P-selectin binding to ZR-75-30 cells. ZR-75-30 cells were incubated with P-selectin chimeras preincubated with modified heparins at the indicated concentrations, followed by a FITC-labeled goat anti-human IgG. The binding events were measured by flow cytometry. The percentage of the positive control was $78.2 \%$. The results are representative of three independent experiments.

altered compared with heparin (sulfate content 27.9\%). We first examined whether the interaction between P-selectin and ZR-75-30 cells could be blocked by heparin or chemically modified heparins (RO-heparin, CR-heparin, 2/3ODS-heparin and N/2/3DS-heparin with sulfate contents of 27.1, 25.2, 19.3 and $15.7 \%$, respectively) (Table I). As shown in Fig. 2, P-selectin binding to ZR-75-30 cells was inhibited to a different extent by chemically modified heparin at concentrations ranging from 5 to $0.1 \mathrm{mg} / \mathrm{ml}$ compared with the positive control. Pre-incubation of P-Fc with heparin or chemically modified heparins $(5 \mathrm{mg} / \mathrm{ml})$ resulted in a $>80 \%$ reduction in P-selectin binding (Table II). At the lower concentration $(0.1 \mathrm{mg} / \mathrm{ml})$, although the extent of inhibition of P-selectin binding was less than that observed at higher concentrations ( $5 \mathrm{mg} / \mathrm{ml}$ ), it was still approximately $\geq 40 \%$ (Table II). These results demonstrate that chemically modified heparins inhibit the binding of ZR-75-30 cells to P-selectin. Notably, the extent of ZR-75-30 cell-P-selectin interaction was relative to the content of sulfate in chemically modified heparin. At the same concentration, N/2/3DS-heparin had the lowest level of sulfation among these heparin derivatives, and was also the least effective at inhibiting P-selectin-mediated adhesion under static conditions. 
Table II. Inhibition values of P-selectin binding to ZR-75-30 cells were obtained from Fig. 2.

\begin{tabular}{lccc}
\hline & \multicolumn{3}{c}{ Inhibition (\%) } \\
\cline { 2 - 4 } & $5 \mathrm{mg} / \mathrm{ml}$ & $1 \mathrm{mg} / \mathrm{ml}$ & $0.1 \mathrm{mg} / \mathrm{ml}$ \\
\hline Heparin $(\mathrm{H})$ & 96.3 & 91.1 & 77.1 \\
RO-H & 95.5 & 88.2 & 71.4 \\
CR-H & 94.5 & 85.7 & 57.3 \\
2/3ODS-H & 92.7 & 73.0 & 53.5 \\
N/2/3DS-H & 84.3 & 69.3 & 36.7 \\
\hline
\end{tabular}

Data are normalized to the positive control $(78.2 \%)$.

Modified heparin inhibits $P$-selectin binding to breast carcinoma cells under flow conditions. To further validate the finding that heparin or chemically modified heparins inhibit P-selectin binding to ZR-75-30 cells, we conducted a flow adhesion assay using CHO cells or activated platelets expressing P-selectin. Compared with non-transfected $\mathrm{CHO}$ cells, P-selectin transfectant significantly increased the binding of ZR-75-30 cells to $\mathrm{CHO}$ monolayers. Heparin and chemically modified heparins at a concentration of $1 \mathrm{mg} / \mathrm{ml}$ reduced the number of ZR-75-30 cells adhering to $\mathrm{CHO}$ cells expressing P-selectin by more than 50\% (Fig. 3A). As shown in the static assay, the treatment of tumor cells with sodium chlorate almost completely abolished tumor cell interaction with P-selectin. Similar results were also obtained using activated platelets (Fig. 3B). These findings indicate that heparin and chemically modified heparins block P-selectinmediated adhesion of ZR-75-30 cells in vitro under flow conditions.

Effects of the glycoproteins on P-selectin binding to breast carcinoma cells. It has been reported that heparan sulfate-like proteoglycans serve as the ligand for P-selectin, and that ZR75-30 cells express a large quantity of heparan sulfate-like proteoglycans (22). However, in ZR-75-30 cells, heparan sulfate-like proteoglycans did not contribute to P-selectin binding. In the present study, we first confirmed the above findings using the $10 \mathrm{E} 4 \mathrm{mAb}$ (which binds to an epitope on heparan sulfate and has been widely used as a research tool in studying heparan sulfate function) and heparinase (which digests heparan sulfate-like proteoglycans on the cell surface) as previously confirmed (data not shown). These results demonstrated that the partial or complete loss of heparan sulfate-like proteoglycans did not impair the ability of ZR75-30 cells to interact with P-selectin. According to previous studies, it was confirmed that P-selectin binds to sialylated, fucosylated or, in some cases, sulfated glycans on glycoproteins, glycolipids, or proteoglycans, indicating that the type of P-selectin ligand involved remains unknown (5-8). To further explore the inhibitory mechanisms of chemically modified heparins, we analyzed the interaction of ZR-75-30 cells with several mAbs, which have been used in identifying P-selectin-binding epitopes. ZR-75-30 cells exhibit deficiencies in KPL 1 and CSLEX-1 binding epitope, indicating that PSGL-1 and sLe ${ }^{\mathrm{x}}$ are not expressed in ZR-75-30 cells
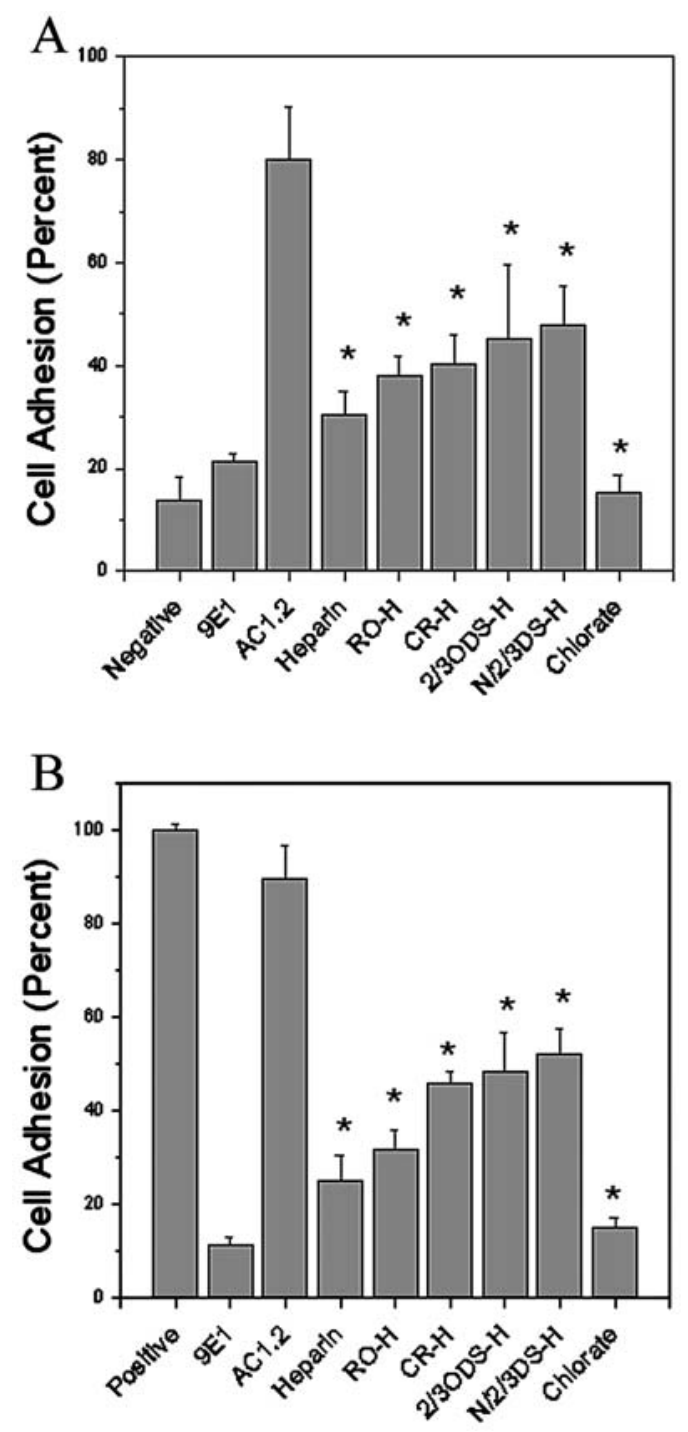

Figure 3. Inhibition of the adherence of ZR-75-30 cells to CHO-P by mAbs and chemically modified heparins under flow conditions. After $30 \mathrm{~min}$ of preincubation with a blocking mAb 9E1 or non-blocking mAb AC1.2, heparin and modified heparins (1 mg/ml), CHO-P monolayers (A) or activated platelets (B) were washed and loaded into the flow chamber, and then tumor cells were perfused on the monolayers. For the sulfated inhibition of tumor cells, ZR-75-30 cells were pre-treated with sodium chlorate (Chlorate). Parent $\mathrm{CHO}$ cells were used as a negative control. The adhesion of tumor cells to the CHO monolayers was measured by videomicroscopy in 10-20 fields of view using a x10 objective lens. Data are the means \pm SE of three to five experiments. Values were calculated as percentages of the positive control ( $20 \pm 6$ cells $/ \mathrm{mm}^{2}$, no inhibitors). ${ }^{*} \mathrm{P}<0.01$ vs. non-blocking mAb AC1.2.

(Fig. 4A). As the dependence of selectin binding on sialylated glycans is well established (23), we used neuraminidase to determine whether there is a relationship between sialylation and the reactivity of P-selectin. Treatment with neuraminidase had no effect on P-selectin binding (Fig. 4B), indicating that P-selectin binds to unsialylated ligands on ZR-75-30 cells. In contrast, treatment of ZR-75-30 cells with trypsin led to a marked decrease in P-selectin binding. Nevertheless, though P-selectin binding was sensitive to trypsin treatment, there remained a small number of ZR-75-30 cells (10\%) which bound to P-selectin. These results indicate that the major ligands for P-selectin on ZR-75-30 cells are glycoproteins other than heparan sulfate-like proteoglycans. 
A

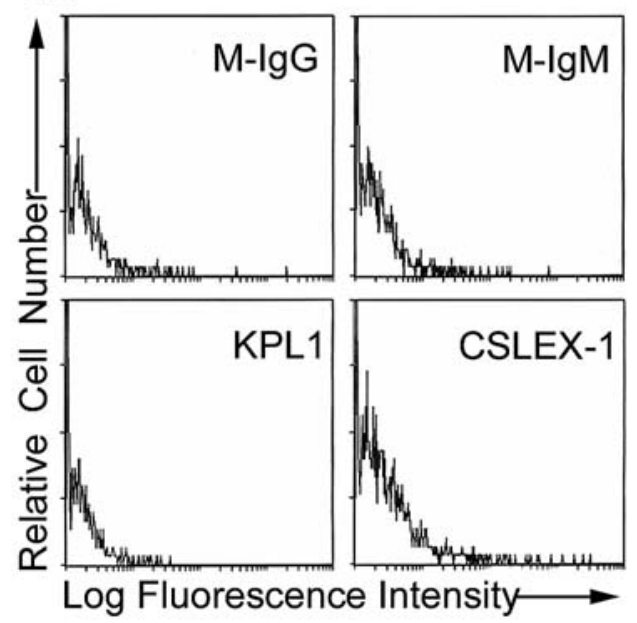

B

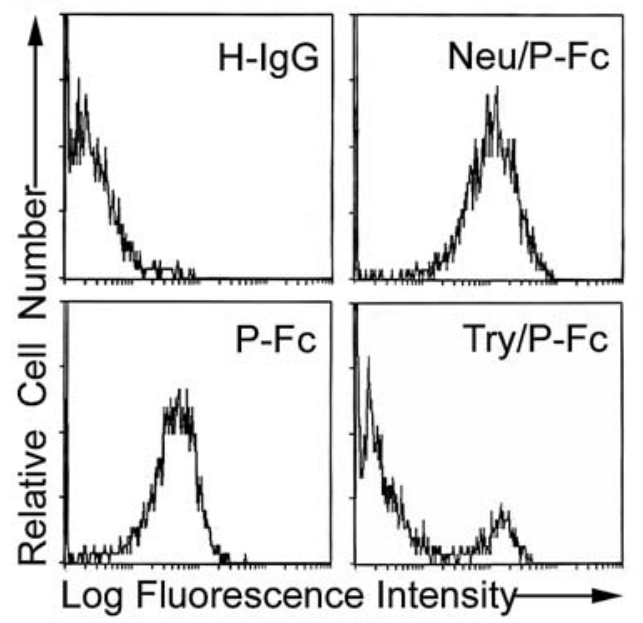

Figure 4. Effect of the glycoproteins on P-selectin binding to ZR-75-30 cells. (A) Tumor cells exhibit deficiencies in sLe ${ }^{\mathrm{x}}$ and PSGL-1 expression, Isotypematched mAbs were used as negative control. KPL-1, an mAb to PSGL-1; CSLEX-1, an mAb to sLe ${ }^{\mathrm{x}}$. (B) Effect of treatment of tumor cells with neuraminidase (Neu) or trypsin (Try) on P-selectin binding. The percentage of P-Fc binding to ZR-75-30 cells is as follow: P-Fc, $89 \%$; Neu, $88 \%$; Try, $10 \%$. The results represent those obtained from three independent experiments.

\section{Discussion}

In this study, we employed breast carcinoma ZR-75-30 cells strongly expressing heparan sulfate-like proteoglycans to investigate the molecular mechanisms by which chemically modified heparins inhibit P-selectin-mediated tumor cell adhesion. Although the interaction of ZR-75-30 cells with P-selectin was inhibited by heparin and chemically modified heparins with low anticoagulant activities, heparan sulfatelike proteoglycans were not involved in this process in $\mathrm{ZR}$ 75-30 cells. Notably, we found that the sulfate content of the chemically modified heparins was relative to their inhibitory effect on P-selectin binding. Also, we inferred that certain types of glycoproteins, distinct from heparan sulfate-like proteoglycans, may play a key role in P-selectin binding to ZR-75-30 cells.

As previously stated, sulfated moieties function as the key determinant for P-selectin recognition $(22,24,25)$. In agreement with this interpretation, heparin is a highly sulfated linear polysaccharide composed of repeating units of disaccharides (glucuronic or iduronic acid and glucosamine) that are either $\mathrm{N}$-sulfated of $\mathrm{N}$-acetylated. The sugar residues may be further $O$-sulfated at the C-6 and C-3 positions of the glucosamine and at the $\mathrm{C}-2$ position of the uronic acid $(26,27)$. Four types of chemically modified heparins used in this study were tested for their sulfate content. Although the sulfate content of chemically modified heparins is lower than that of heparin, chemically modified heparins still contain a large amount of sulfate groups (28). In the present study, the results indicated that the content of the sulfate of chemically modified heparin was relative to the inhibitory effect on P-selectin binding to ZR-75-30 cells (Table II). Therefore, the inhibition mechanism may be partially due to the sulfated residues in chemically modified heparins in this process. Recently, some chemically modified heparins with low or no anticoagulant activities were examined regarding their inhibition of metastasis but not primary tumor growth (16-18). This led us to investigate the extensive use of chemically modified heparins. We provide evidence that chemically modified heparins with reduced anticoagulant activities inhibit P-selectin binding to breast carcinoma cells in addition to colon carcinoma and non-small cell lung cancer cells. Furthermore, Stevenson et al showed chemically modified, non-anticoagulant heparins to be even more effective (19), indicating that they are more promising for use as P-selectin antagonists.

According to the literature $(3,4), \mathrm{P}$-selectin binds to sialylated, fucosylated or, in some cases, sulfated glycans on glycoproteins, glycolipids or proteoglycans. Thus, the type of P-selectin ligand involved remains unknown. In the present study, we tried to rule out certain types of P-selectin ligands on ZR-75-30 cells. Sialylated glycans and heparan sulfate-like proteoglycans were not involved in P-selectin binding to ZR75-30 cells. However, these findings do not elucidate which types of structures are responsible for P-selectin binding. Glycoproteins play various roles in this process. Meanwhile, other ligands remained, as the relative blocking ability of trypsin treatment was $90 \%$; incomplete compared to the human IgG negative control (Fig. 4B). Though we were unable to clearly identify the type of P-selectin ligand on ZR-75-30 cells, chemically modified heparins with decreased anticoagulant activities did block the interaction of P-selectin with tumor cells. This point is of critical importance, as P-selectin-ligand interactions may be a good target for the blocking of breast cancer metastases. In addition, it has been reported that chondroitin sulfate glycosaminoglycans serve as major P-selectin ligands in metastatic breast cancer cell lines, and that heparin can attenuate this interaction (29). Breast cancer is the leading cause of cancer-related death in women. Advanced breast cancer in particular is commonly associated with hematogenous metastasis, which is accompanied by serious complications. Further detailed study involving chemically modified heparins with low anticoagulant activities is warranted for the treatment of breast cancer metastases. 


\section{Acknowledgements}

We thank Dr Guido David (Center for Human Genetics, University of Leuven, Leuven, Belgium) for providing 10E4 $\mathrm{mAb}$ and Dr Olivier Spertini. (Division and Central Laboratory of Hematology, University of Lausanne, Lausanne, Switzerland) for providing CSLEX-1 mAb. This study was supported by grants from the National Natural Science Foundation of P.R. China (30570927, 30670471), the Specialized Research Fund for the Doctoral Program of Higher Education (2006200003) and the Natural Science Foundation of Jilin Province (200705488-1).

\section{References}

1. McEver RP, Moore KL and Cummings RD: Leukocyte trafficking mediated by selectin-carbohydrate interactions. J Biol Chem 270 : 11025-11028, 1995.

2. Vestweber D and Blanks JE: Mechanisms that regulate the function of the selectins and their ligands. Physiol Rev 79: 181-213, 1999.

3. Kansas GS: Selectins and their ligands: Current concepts and controversies. Blood 88: 3259-3287, 1996.

4. Varki A: Selectin ligands: Will the real ones please stand up? J Clin Invest 99: 158-162, 1997.

5. Dardik R, Kaufmann Y, Savion N, Rosenberg N, Shenkman B and Varon D: Platelets mediate tumor cell adhesion to the subendothelium under flow conditions: Involvement of platelet GPIIb-IIIa and tumor cell alpha(v) integrins. Int J Cancer 70: 201-207, 1997.

6. Fryer A, Huang YC, Rao G, Jacoby D, Mancilla E, Whorton R, Piantadosi CA, Kennedy T and Hoidal J: Selective O-desulfation produces nonanticoagulant heparin that retains pharmacological activity in the lung. J Pharmacol Exp Ther 282: 208-219, 1997.

7. Goetz DJ, Ding H, Atkinson WJ, Vachino G, Camphausen RT, Cumming DA and Luscinskas FW: A human colon carcinoma cell line exhibits adhesive interactions with P-selectin under fluid flow via a PSGL-1-independent mechanism. Am J Pathol 149: 1661-1673, 1996.

8. Jayson GC, Lyon M, Paraskeva C, Turnbull JE, Deakin JA and Gallagher JT: Heparan sulfate undergoes specific structural changes during the progression from human colon adenoma to carcinoma in vitro. J Biol Chem 273: 51-57, 1998.

9. Aruffo A, Kolanus W, Walz G, Fredman P and Seed B: CD62/P-selectin recognition of myeloid and tumor cell sulfatides. Cell 67: 35-44, 1991.

10. Needham LK and Schnaar RL: The HNK-1 reactive sulfoglucuronyl glycolipids are ligands for L-selectin and P-selectin but not E-selectin. Proc Natl Acad Sci USA 90: 1359-1363, 1993.

11. Wang LC, Brown JR, Varki A and Esko JD: Heparin's antiinflammatory effects require glucosamine 6-O-sulfation and are mediated by blockade of L- and P-selectins. J Clin Invest 110: 127-136, 2002.

12. Smorenburg SM and van Noorden CJF: The complex effects of heparins on cancer progression and metastasis in experimental studies. Pharmacol Rev 53: 93-105, 2001.
13. Zacharski LR and Loynes JT: The heparins and cancer. Curr Opin Pulm Med 8: 379-382, 2002.

14. Rabenstein DL: Heparin and heparan sulfate: structure and function. Nat Prod Rep 19: 312-331, 2002.

15. Wei M, Tai GH, Gao YG, Li N, Huang BQ, Zhou YF, Hao S and Zeng XL: Modified heparin inhibits P-selectin-mediated cell adhesion of human colon carcinoma cells to immobilized platelets under dynamic flow. J Biol Chem 279: 29202-29210, 2004.

16. Stevenson JL, Choi SH and Varki A: Differential metastasis inhibition by clinically relevant levels of heparins - Correlation with selectin inhibition, not antithrombotic activity. Clin Cancer Res 11: 7003-7011, 2005.

17. Kragh M and Loechel F: Non-anti-coagulant heparins: A promising approach for prevention of tumor metastasis. Int $\mathbf{J}$ Oncol 27: 1159-1167, 2005.

18. Kragh M, Binderup L, Hjarnaa PJV, Bramm E, Johansen KB and Petersen CF: Non-anti-coagulant heparin inhibits metastasis but not primary tumor growth. Oncol Rep 14: 99-104, 2005.

19. Stevenson JL, Varki A and Borsig L: Heparin attenuates metastasis mainly due to inhibition of P- and L-selectin, but nonanticoagulant heparins can have additional effects. Thromb Res 120: S107-S111, 2007.

20. Burdick MM, McCaffery JM, Kim YS, Bochner BS and Konstantopoulos K: Colon carcinoma cell glycolipids, integrins, and other glycoproteins mediate adhesion to HUVECs under flow. Am J Physiol Cell Physiol 284: C977-C987, 2003.

21. Gao YG, Wei M, Zheng S, Ba XQ, Hao S and Zeng XL: Chemically modified heparin inhibits the in vitro adhesion of nonsmall cell lung cancer cells to P-selectin. J Cancer Res Clin Oncol 132: 257-264, 2006.

22. Ma YQ and Geng JG: Obligatory requirement of sulfation for $\mathrm{P}$-selectin binding to human salivary gland carcinoma Acc-M cells and breast carcinoma ZR-75-30 cells. J Immunol 168: 1690-1696, 2002.

23. Mannori G, Crottet P, Cecconi O, Hanasaki K, Aruffo A, Nelson RM, Varki A and Bevilacqua MP: Differential colon cancer cell adhesion to E-, P-, and L-selectin: role of mucintype glycoproteins. Cancer Res 55: 4425-4431, 1995.

24. Skinner MP, Lucas CM, Burns GF, Chesterman CN and Berndt MC: GMP-140 binding to neutrophils is inhibited by sulfated glycans. J Biol Chem 266: 5371-5374, 1991.

25. Lin HY, Harris TL, Flannery MS, Aruffo A, Kaji EH, Gorn A, Kolakowski LF, Lodish HF and Goldring SR: Expression cloning of an adenylate cyclase-coupled calcitonin receptor. Science 254: 1022-1024, 1991.

26. McLean JAY: The discovery of heparin. Circulation 19: 75-78, 1959.

27. Nugent MA: Heparin sequencing brings structure to the function of complex oligosaccharides. Proc Natl Acad Sci USA 97: 10301-10303, 2000.

28. Varki NM and Varki A: Heparin inhibition of selectin-mediated interactions during the hematogenous phase of carcinoma metastasis: Rationale for clinical studies in humans. Semin Thromb Hemost 28: 53-66, 2002.

29. Monzavi-Karbassi B, Stanley JS, Hennings L, Jousheghany F, Artaud C, Shaaf S and Kieber-Emmons T: Chondroitin sulfate glycosaminoglycans as major P-selectin ligands on metastatic breast cancer cell lines. Int J Cancer 120: 1179-1191, 2007. 